Article

\title{
The Effect of Laser Peening without Coating on the Fatigue of a 6082-T6 Aluminum Alloy with a Curved Notch
}

\author{
Enrico Troiani $(10$ and Nicola Zavatta *(1) \\ Department of Industrial Engineering, University of Bologna, 47121 Forlì, Italy \\ * Correspondence: enrico.troiani@unibo.it
}

Received: 20 May 2019; Accepted: 26 June 2019; Published: 28 June 2019

check for updates

\begin{abstract}
Laser shock peening has established itself as an effective surface treatment to enhance the fatigue properties of metallic materials. Although a number of works have dealt with the formation of residual stresses, and their consequent effects on the fatigue behavior, the influence of material geometry on the peening process has not been widely addressed. In this paper, Laser Peening without Coating $(\mathrm{LPwC})$ is applied at the surface of a notch in specimens made of a 6082-T6 aluminum alloy. The treated specimens are tested by three-point bending fatigue tests, and their fatigue life is compared to that of untreated samples with an identical geometry. The fatigue life of the treated specimens is found to be 1.7 to 3.3 times longer. Brinell hardness measurements evidence an increase in the surface hardness of about $50 \%$, following the treatment. The material response to peening is modelled by a finite element model, and the compressive residual stresses are computed accordingly. Stresses as high as $-210 \mathrm{MPa}$ are present at the notch. The ratio between the notch curvature and the laser spot radius is proposed as a parameter to evaluate the influence of the notch.
\end{abstract}

Keywords: laser shock peening; fatigue; notch; aluminium alloys; finite element method

\section{Introduction}

Laser Shock Peening (LSP) is a technology that makes use of shock waves induced by a laser to improve the mechanical properties of a metallic component. Short laser pulses (1-50 ns) with a high-power intensity are shot at the surface of the component. The laser beam vaporizes a superficial layer of the treated material, with the local formation of high-pressure plasma, as noted by the authors of [1]. Fabbro et al. [2] studied the use of a transparent overlay as an effective method to confine the generated plasma. This results in the formation of intense shock waves, which induce high residual stresses in the surrounding material, as shown by Sano et al. [3].

Conventional laser peening usually employs an ablative layer (i.e., a coating applied on the surface of the material) to prevent damage to the metal surface. Another technique also exists, called Laser Peening without Coating ( $\mathrm{LPwC})$, in which no ablative layer is used and the treated specimen is immersed in water during exposure to laser pulses. Compared with conventional laser peening, LPwC does not require a specific surface preparation and can be performed by commercial Nd:YAG lasers, which makes it particularly appealing for a number of applications.

The effects of the LSP-induced residual stresses on the fatigue of aluminum alloys are well documented in the literature. A review by Montross et al. [4] reported an improved fatigue life of $\mathrm{Al}$ 2024 and Al 7075 specimens treated with laser peening, while the authors of [5] show an effective reduction in the fatigue crack growth rate in a laser-peened 6061-T6 aluminum alloy. Gao [6] noted that the superior performances of laser shock peening compared with mechanical shot peening are due to deeper compressive stresses and a better surface finish. 
Similar improvements of the fatigue behavior have been reported for laser peening without coating. In 2006, Sano et al. [7] observed a substantial prolongation of the fatigue life of an LPwC-treated $\mathrm{AC} 4 \mathrm{CH} \mathrm{Al}$ alloy, even though an increase of the surface roughness was found. Similar results were obtained by the authors of [8] for AA7075-T73 open-hole specimens. A recent review [9] reports enhanced fatigue properties for a wide class of metals treated with $\mathrm{LPwC}$, including 6061 and 6082 Al alloys.

Geometry is known to play a role in the efficacy of LSP, as shown in the literature [10], where the effect of LSP on thin AA2024 panels typical of aeronautical applications were studied, and retarded crack propagation was observed. A work by Troiani et al. [11] highlights the potential drawbacks of the LSP of thin panels, depending on the selected peening path. Of particular interest is the influence of geometric discontinuities on the peening process. Yang [12] reported an improved fatigue life of $\mathrm{Al}$ 2024 specimens with pre-existing holes treated with LSP; on the other hand, Ivetic et al. [13] showed that the interaction between laser peening and an open hole in aluminum panels could potentially result in a decreased fatigue life. Dorman [14] addressed the presence of scribe defects and their effects on the fatigue life of LSP-treated 2024 aluminum alloys.

Although curved notches are often critical for the nucleation of fatigue cracks, only a few works have addressed the effects of laser shock peening on a curved surface. Notably, Peyre [15] studied the effects of laser shock peening in specimens with a curved notch. The authors reported extended fatigue lives of laser-peened specimens compared with mechanically shot-peened and untreated ones. They also measured high compressive stresses around the notch. Vasu and Grandhi [16] analyzed the residual stress field induced by laser peening on a curved surface by means of a finite element model. The compressive stress was found to increase in a concave geometry, as compared with a flat or convex surface. The increase was related to the radius of the curvature, in that the smaller the radius, the higher the compressive stress.

This work aims to study the effects of laser peening without coating applied at a circular notch, as shown in Figure 1. In particular, the effects of the process on the fatigue behavior are investigated by three-point bending specimens, while the residual stresses at the notch are computed by means of a finite element model.

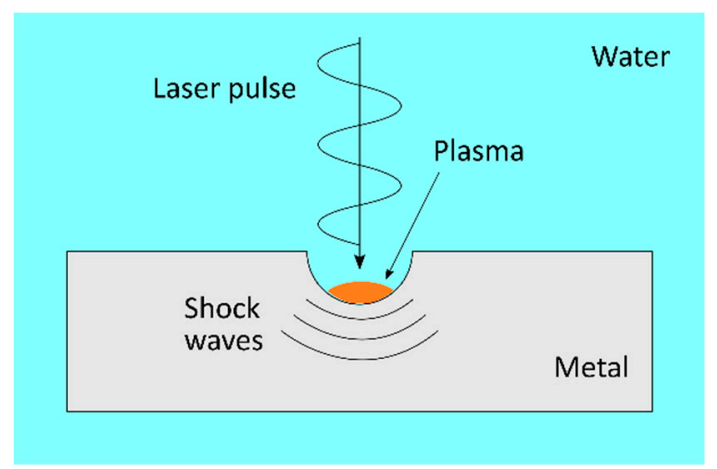

Figure 1. Application of the Laser Peening without Coating ( $\mathrm{LPwC}$ ) process to a notched specimen.

\section{Materials and Methods}

\subsection{Characteristics of the Baseline Material}

The specimens used for the analysis were made of aluminum alloy 6082-T6, with the geometry given in Figure 2. The specimens were machined out of a $400 \times 260 \times 20 \mathrm{~mm}^{3}$ plate, with a circular notch milled at the center. A Mitutoyo Surface Roughness Tester (Mitutoyo Italiana, Lainate, Italy) was used to measure the surface roughness at the notch-five measurements were taken on each specimen and the nominal roughness was found to be equal to $3.2 \mu \mathrm{m}$. The thickness of the specimen was high enough, so that it did not warp during the peening process. The geometry of the specimen was similar 
to that reported in the literature [15] for three-point bending fatigue tests, with the central notch acting as a stress concentration for the easier localization of the fatigue crack nuclei.

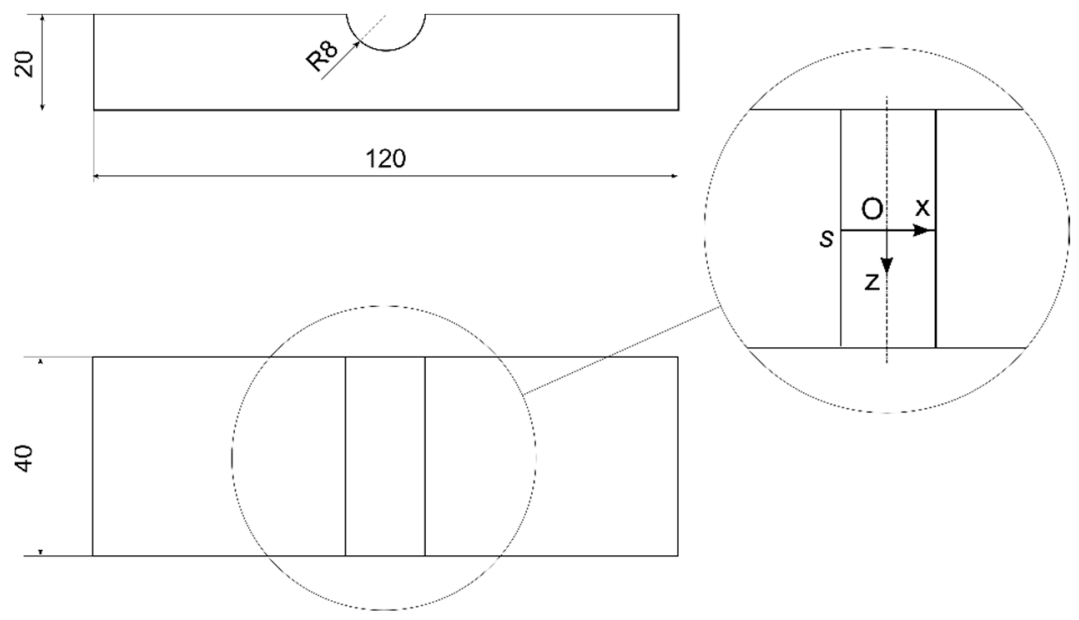

Figure 2. Specimen geometry. The midline path $(s)$ and the local coordinates are shown in the detailed view of the notch.

\subsection{Laser Peening Treatment}

The LPwC treatment was performed in the Department of Industrial Engineering Laboratories of the University of Bologna (Bologna, Italy). The setup used for the laser shock peening is shown in Figure 3.



Figure 3. Setup used for the laser shock peening without coating treatment.

The laser source was provided by a Nd:YAG pulsed laser produced by Quanta Systems (Samarate, Italy). Its settings are as follows: wavelength of $1064 \mathrm{~nm}$, nominal pulse energy of $1.8 \mathrm{~J}$, and a pulse duration equal to $8 \mathrm{~ns}$. The nominal laser power density was $7 \mathrm{GW} / \mathrm{cm}^{2}$. 
The peening was applied in the central part of the notch on a rectangular area of $40 \times 4 \mathrm{~mm}^{2}$, as shown in Figure 4a. A circular laser spot size of $2 \mathrm{~mm}$ in diameter was used, with a distance of $0.25 \mathrm{~mm}$ between two adjacent spot-centers. A spot overlapping of $75 \%$, as shown in Figure $4 \mathrm{~b}$, was chosen so as to attain complete coverage of the treated area on a single layer, as discussed in the literature [13]. This resulted in a pulse density equal to 1600 pulses $/ \mathrm{cm}^{2}$.

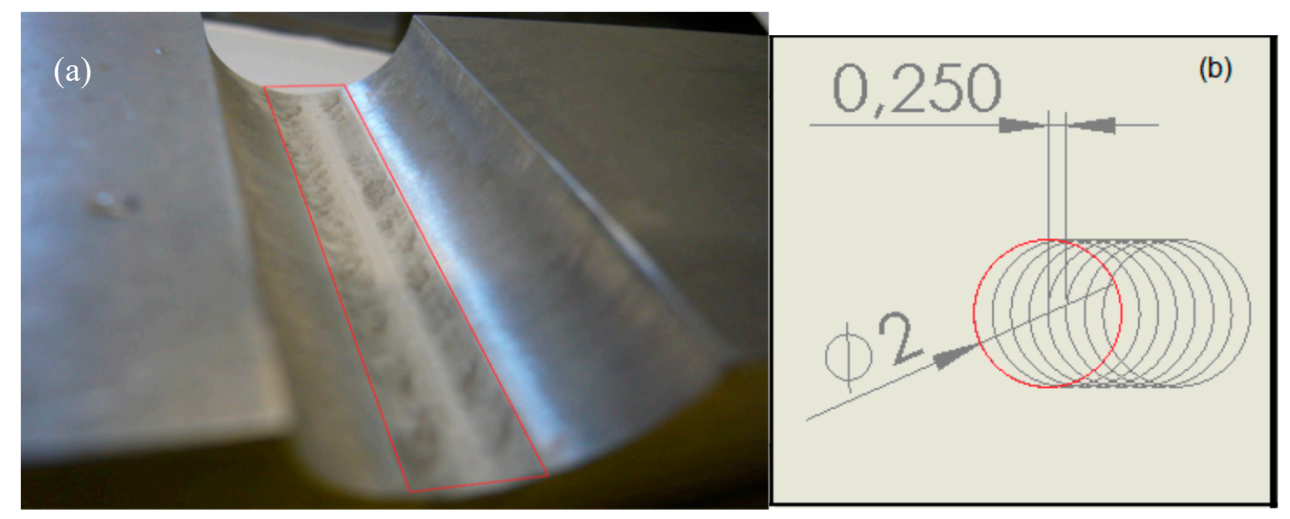

Figure 4. (a) Detailed view of the peened zone. (b) The treated area is bounded in the red box.

\subsection{Fatigue Testing}

The three-point bending fatigue tests were performed at the MaSTeR Lab laboratories in Forli (University of Bologna), with the use of a $100 \mathrm{kN}$ servo-hydraulic testing machine (Italsigma, Forlì, Italy). The experimental setup is illustrated in Figure 5. The tests were conducted under force-controlled conditions at four different stress levels, with a constant $\mathrm{R}$-ratio of $\mathrm{R}=0.1$. The stress concentration factor for the given specimen configuration was $\mathrm{Kt}=1.3$, which resulted in maximum stresses at the notch ranging from 220 to $260 \mathrm{MPa}$.

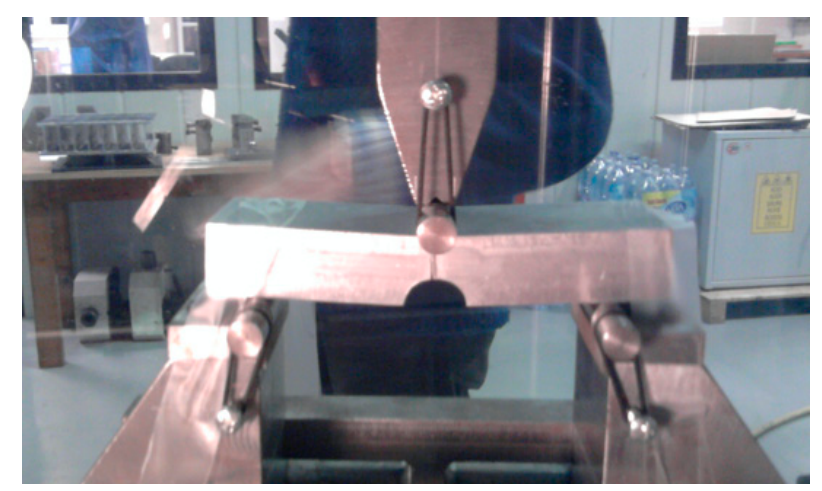

Figure 5. Experimental setup for three-point bending fatigue tests.

\subsection{Hardness Measurement}

The hardness measurements were performed in order to quantify the effect of the LPwC treatment on the surface hardness of the treated specimens. The measurements were conducted according to the E10-18 standard test procedure for Brinell hardness [17]. The sample used for testing was taken from the LPwC-treated specimens, and was additionally machined in order to accommodate the hardness testing machine. Five measurements were performed, two in the central, peened section of the specimen (Figure 6), and three on the untreated part of the sample (Figure 7). As the diameter of the indentation (e.g., about $1 \mathrm{~mm}$ ) is small compared with the radius of the notch, the effect of the curvature was not considered. 


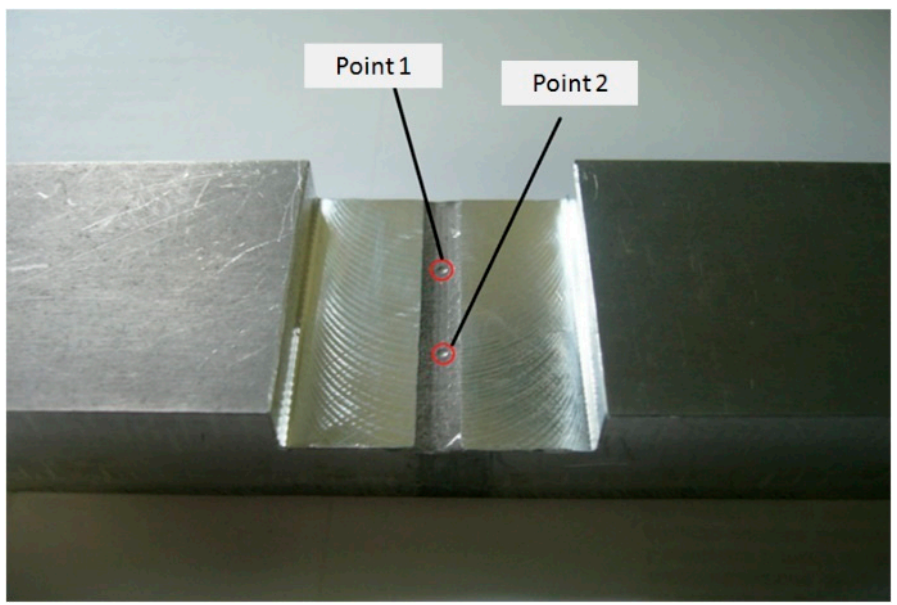

Figure 6. Central hardness measurement points. The two locations used for the Brinell hardness measurement in the region treated with $\mathrm{LPwC}$ are shown.

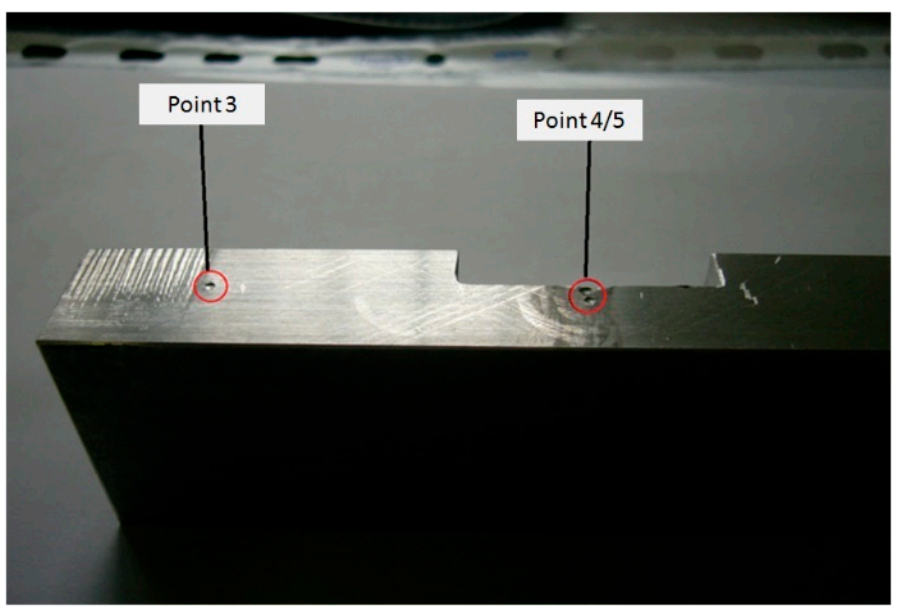

Figure 7. Side hardness measurement points. Locations considered for hardness measurement of the untreated material.

\subsection{Numerical Model}

The residual stresses induced by laser peening were computed by finite element analyses in the commercial software Abaqus/Explicit v6.12 (Dassault Systemes, Paris, France). Several models can be found in the literature to characterize the material response in the context of laser shock peening. The Johnson-Cook constitutive model considers the effect of large strains and high strain rates on material behavior, and was applied in an explicit/implicit finite element model by the authors of [18]. Ivetic et al. [8] optimized the non-linear response through full-explicit numerical analyses, taking into account the actual overlapping of the peening shots. Nevertheless, the material response to the shock waves propagation can be thought of as a condition of high-strain rate cyclic loading. The effect of the cyclic deformation induced by laser peening was already studied by Angulo et al. [19]. In this regard, a nonlinear isotropic/kinematic hardening plastic model, which also includes the change of properties due to the Bauschinger effect, can be used to simulate the material behavior. This model consists of isotropic hardening (Equation (1)) plus a nonlinear kinematic hardening component. The back stresses in kinematic hardening can be computed by Equation (2), according to Chaboche [20].

$$
\begin{gathered}
\sigma_{Y}=\sigma_{0}+Q_{\infty}\left[1-\exp \left(-b \varepsilon^{p l}\right)\right] \\
d \alpha=C d \varepsilon^{p l}-\gamma \alpha\left|d \varepsilon^{p l}\right|
\end{gathered}
$$


The material properties of $\mathrm{Al} 6082-\mathrm{T} 6$ were selected according to the works by Chen et al. [21] and Chen et al. [22], which present thorough measurements of the hardening parameters, including testing at high strain rates via a split-Hopkinson tension bar. The maximum strain rate measured in the tests was around $3400 \mathrm{~s}^{-1}$, which is lower than that occurring during laser peening (i.e., in the order of $\left.10^{6} \mathrm{~s}^{-1}\right)$, according to the authors of [15]. However, $\mathrm{Al}$ 6082-T6 is reported to have a low sensitivity on the strain rate. Moreover, a study by Langer et al. [23] investigated the effects of using conventional test data to model the laser peening process; they concluded that consistent results could be obtained with strain rates in the order of $10^{3} \mathrm{~s}^{-1}$ (i.e., similar to those encountered in the literature of $[21,22]$ ). The hardening parameters input into the material model are summarized in Table 1.

Table 1. Kinematic hardening parameters for Al 6082-T6.

\begin{tabular}{ccccc}
\hline $\begin{array}{c}\sigma_{0} \\
{[\mathrm{MPa}]}\end{array}$ & $\begin{array}{c}\boldsymbol{C} \\
{[\mathrm{MPa} \text { s] }}\end{array}$ & $\begin{array}{c}\gamma \\
{[\mathbf{s}]}\end{array}$ & $\begin{array}{c}\boldsymbol{Q}_{\infty} \\
{[\mathbf{M P a}]}\end{array}$ & $\begin{array}{c}\boldsymbol{b} \\
{[-]}\end{array}$ \\
\hline 319 & 3211.7 & 25 & 64.5 & 24.3 \\
\hline
\end{tabular}

Instead of direct modelling of the laser and the plasma layer, the equivalent pressure of the plasma was considered, following the approach described by the authors [18]. As a result of the low energy of the laser pulses and the short pulse duration, the thermal effect on the material is negligible compared to the effect of shock waves, as reported by the authors of [24]. The simulation is split into the following two steps: first, pressure is applied in the peened area and the waves propagate elastically in the material; second, the load and constraints are released and residual stresses develop, following material relaxation. An excessive computational time would have been required to model multiple laser shots. As a result, only one single shot was modelled, with a spot size equivalent to the treated area of the specimens.

The pressure exerted by the plasma depends on the laser parameters, namely, wavelength, power density, and pulse duration. The laser spot was simulated by applying a pressure load with a triangular temporal profile and uniform spatial distribution. The triangular temporal profile approximates the results reported in the literature [25] for a water confined plasma, with a maximum pressure of $4 \mathrm{GPa}$ attained after $25 \mathrm{~ns}$, which decays to zero at $50 \mathrm{~ns}$.

The geometry of the finite element model reproduces that of the real coupons, cut on the two sides so that the total width is $48 \mathrm{~mm}$. The size of the peened region is $40 \times 4 \mathrm{~mm}^{2}$. The mesh size is not homogeneous, as shown in Figure 8 , as thin elements are needed in the thickness direction to capture the residual stress gradient at the notch; the minimum element is $0.13 \times 0.20 \times 0.03 \mathrm{~mm}^{3}$. Clamped boundary conditions are applied at the edges of the specimen, and the bottom surface is constrained against displacements.

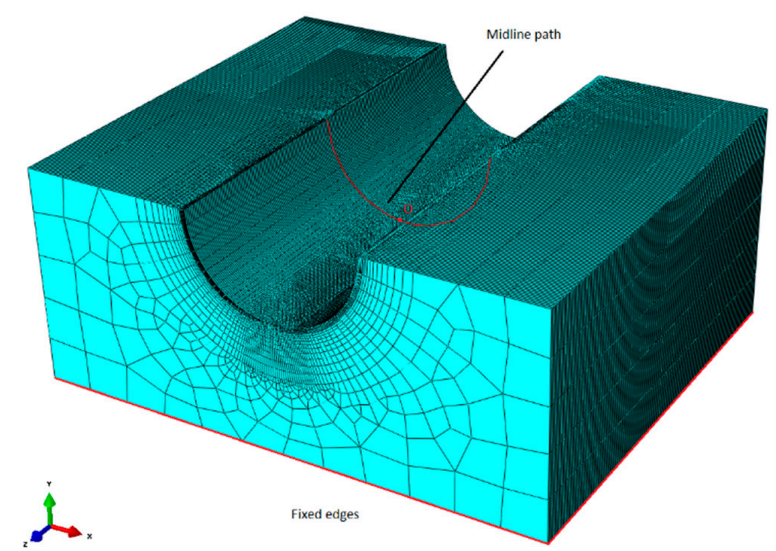

Figure 8. Finite element model of the specimen. Built-in constraints at the bottom edges are shown. The midline path is highlighted in red and its origin is denoted by the letter $\mathrm{O}$. 


\section{Results}

\subsection{Fatigue Tests}

A total of eight specimens were tested-four samples (denoted as 2, 3, 4, and 5) were LPwC-treated, as described above; the other four $(6 \mathrm{~B}, 7 \mathrm{~B}, 8 \mathrm{~B}$, and $9 \mathrm{~B})$ were untreated and served as a baseline for comparison. The Maximum Stress-Number of cycles (S-N) results of the two cases are plotted in Figure 9. Two distinct S-N curves are fitted through the data of the peened and unpeened samples using the least-squares method. Even if four specimens are not sufficient for constructing a statistically significant S-N curve, the trends obtained from fatigue testing are very clear. The fatigue life of the treated specimens was found to be longer for all load levels, with a maximum increase equal to 3.34 times the baseline value.

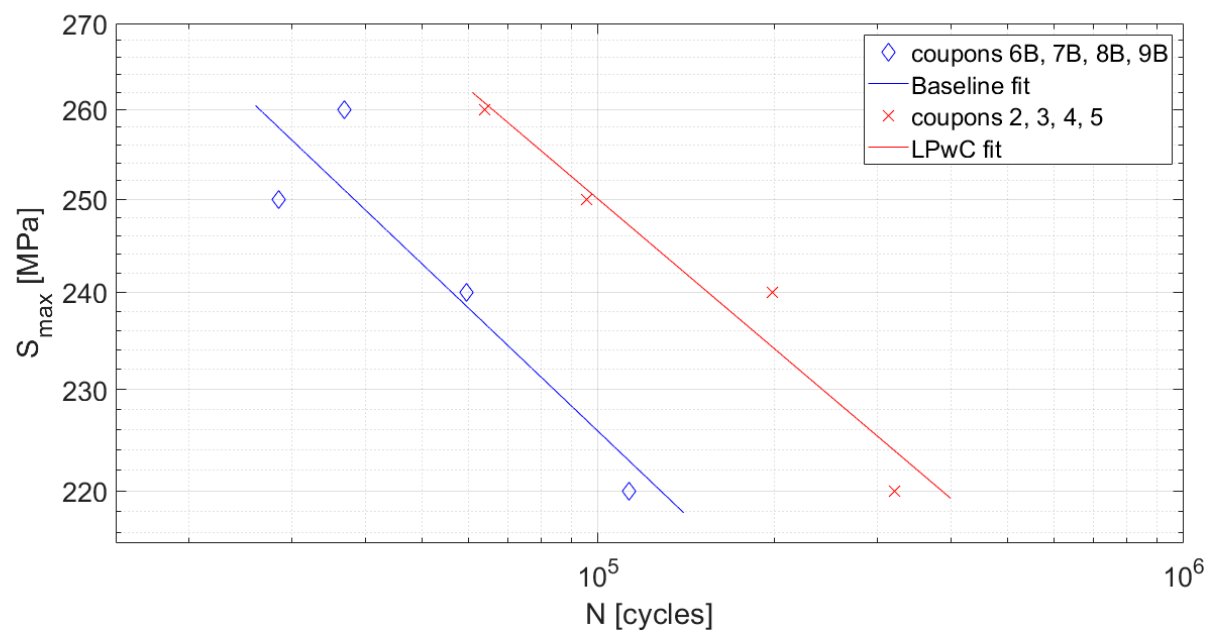

Figure 9. S-N curves from the fatigue tests. The maximum nominal stresses vs fatigue lives of the tested specimens are plotted. Least-square fittings of the untreated and peened samples are shown in red and blue, respectively.

\subsection{Hardness Measurement}

The measured hardness values are collected in Table 2. The average hardness measured in the unpeened region, around $120 \mathrm{HB}$, is $34 \%$ higher than the nominal hardness reported by the manufacturer, which is a result of the milling operation used to cut the specimens. Comparing this to the measurements at the notch, it shows a hardness increase of about $50 \%$ after LPwC.

Table 2. Brinell hardness measurement results. LSP-laser shock peening.

\begin{tabular}{ccc}
\hline Measurement Point & Surface State & Brinell Hardness \\
\hline 1 & LSP-treated & $178 \mathrm{HB}$ \\
2 & LSP-treated & $185 \mathrm{HB}$ \\
3 & As machined & $123 \mathrm{HB}$ \\
4 & As machined & $117 \mathrm{HB}$ \\
5 & As machined & $120 \mathrm{HB}$ \\
\hline
\end{tabular}

\subsection{FEM Results}

The distribution of the normal stress $\sigma_{x x} \mathrm{n}$ the peened area is shown in Figure 10. The treated area extends $2 \mathrm{~mm}$ left and right from the origin $(\mathrm{O})$, also shown in the figure. Compressive residual stresses are present in this region, with compression peaks as high as $210 \mathrm{MPa}$. The $\sigma_{x x}$ component shown here acts in the same direction of the bending stress in the tests. The finite elements analysis also provides information on the in-depth distribution of the stresses. The in-depth residual stress $\sigma_{x x}$ in Figure 11 is 
computed at location $\mathrm{O}$, perpendicularly to the surface of the notch. A compressive peak is found at a depth of about $0.2 \mathrm{~mm}$, while a strong stress gradient is observed close to the surface. At depths greater than $0.7 \mathrm{~mm}$, a tractive residual stress field is present as a consequence of equilibrium.

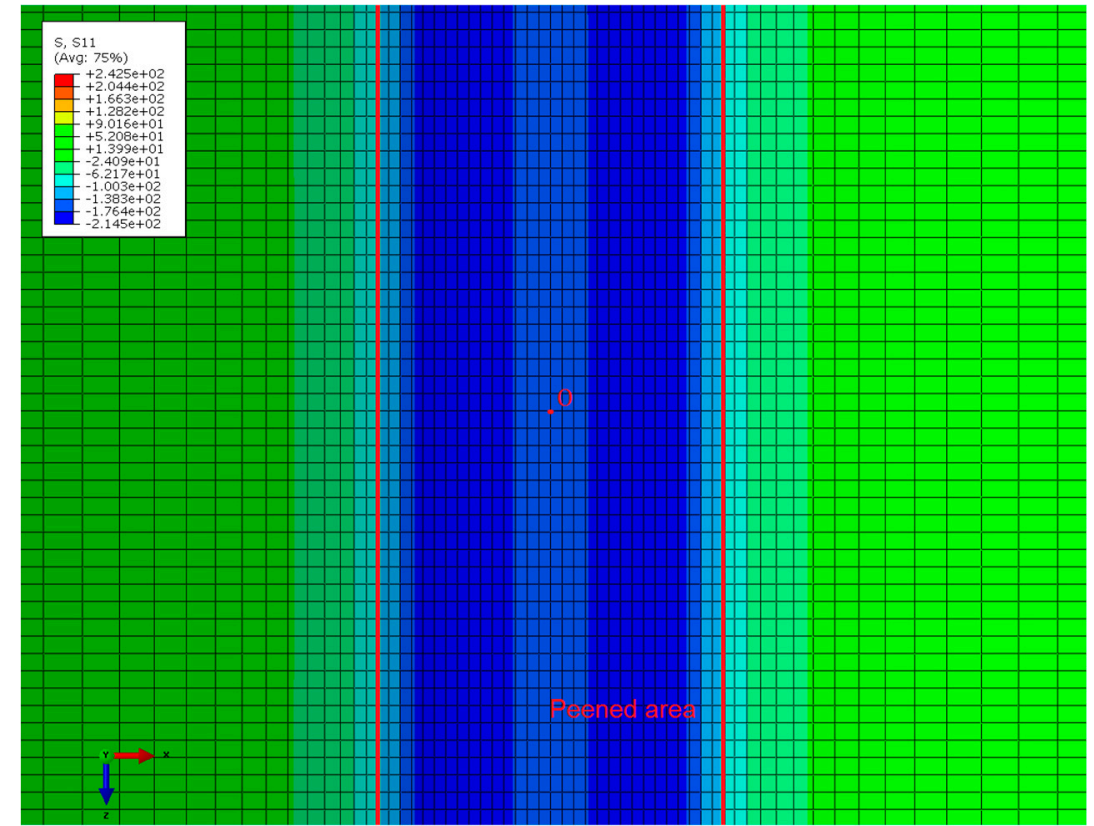

Figure 10. Distribution of residual stress $\sigma_{x x}$ in the peened strip, bounded by the red lines.

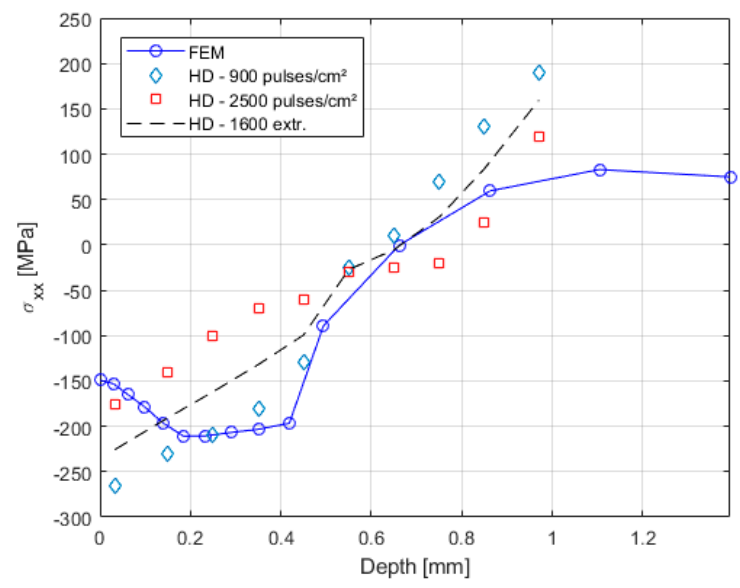

Figure 11. Residual stress distribution in the in-depth direction. The FEM results are plotted together with the hole drilling measurements in the literature [22] (blue and red dots) and to their extrapolation (dashed line).

\section{Discussion}

The tests conducted on the untreated and peened specimens show a clear improvement of the fatigue behavior after laser peening. For all of the applied stress levels, a net increase of the fatigue life was observed. The fatigue life of the baseline samples (i.e., 110 kcycles at $220 \mathrm{MPa}$ ) is in line with previous findings by the authors of [26], who reported about 120 kcycles at $230 \mathrm{MPa}$ in four-point bending tests of Al 6082 specimens. The fatigue life of the LPwC-treated samples shows an improvement from 1.73 to 3.34 times the baseline value. These findings can be compared to the results in the literature [15], which include the three-point bending of notched specimens treated with conventional laser peening with an ablative layer. The authors reported a net improvement following LSP, with the fatigue lives enhanced by a factor of 10 compared to the baseline; albeit, it should be 
noted that a different material, namely $\mathrm{Al} 7075$, was tested. For a better characterization of the scatter in the S-N curves of $\mathrm{Al} 6082$, additional testing would be recommended, which falls beyond the scope of this work.

The Brinell hardness measurements evidence a surface hardness increase in the order of $50 \%$ in the peened region. Trdan et al. [24] already reported a micro-hardness increase for Al 6082-T651 after LPwC. A further study [27] of the microstructural evolution of Al 6082-T651 evidenced an increase of the dislocation density after $\mathrm{LPwC}$, with the production of ultra-fine and nano-grains, and related it to the induced residual stresses. In light of this, the increase of dislocation density can be seen as the prime driver of the enhanced surface hardness, as well as being involved in the plastic deformation, which results in the formation of residual stresses.

The improved fatigue life of the peened samples is ascribed mainly to the compressive residual stresses induced by the process. The numerical results confirm that compressive stresses are present at the notch surface along the treated strip, as shown in Figure 10; in particular, compressive residual stresses $\sigma_{x x}$ are computed at the notch. The three-point bending tests produce a tensile stress $\sigma_{x x}$ at the notch, which tends to propagate a crack, normal to the x-direction. The compressive residual stress $\sigma_{x x}$ contributes to closing the crack by decreasing the effective stress intensity factor range at the crack tip. For metallic materials, this is known to generate a reduction of the crack growth rate, thus postponing the specimen's failure. This mechanism could explain the prolonged fatigue life of the treated samples observed in Figure 9.

The computed in-depth residual stress field is shown in Figure 11. Also plotted are the experimental findings by the auhors of [24] obtained by hole drilling (HD) measurements on flat $\mathrm{Al} 6082$ specimens treated with LPwC. As two different pulse densities were used in the literature [25], namely 900 and 2500 pulses $/ \mathrm{cm}^{2}$, a direct comparison with the numerical results presented here for a density of 1600 pulses $/ \mathrm{cm}^{2}$ is somewhat biased. To this end, an extrapolation of the measurements to a density equal to 1600 pulses $/ \mathrm{cm}^{2}$ is also shown; this is obtained by linearly interpolating the measurements for the upper and lower pulse density. The maximum compressive residual stresses calculated by FEM are about $-210 \mathrm{MPa}$, which is $16 \%$ higher than the value of $-180 \mathrm{MPa}$ extrapolated from the measurements at the same depth.

The model predicts a compressive stress gradient close to the surface, which is not observed in the measurements. However, the first measurement by the authors of [25] was taken at a depth of $0.1 \mathrm{~mm}$, and the points at $0.03 \mathrm{~mm}$ are the result of the method used for post-processing, as explicitly pointed out by the authors themselves. Remarkably, a similar stress gradient was found by the authors of [28] in a numerical study of a flat $\mathrm{Al} 2050$ specimen. When validating the numerical results against $\mathrm{X}$-ray diffraction measurements, the authors reported on the difficulty of measuring the residual stress gradient. In light of this, the steep stress gradient observed in the numerical results should not be regarded as an effect strictly related to the curvature at the notch. Interestingly, the depth of the compressive region seems to be basically unaffected by the presence of the notch, with compressive residual stresses extending to about $0.7 \mathrm{~mm}$ deep, similarly to the case of the unnotched specimen.

The effect of the notch on the residual stress can be estimated as follows. Vasu and Grandhi [16] reported that the effect of the surface curvature on the residual stresses induced by peening strongly depends on the radius of curvature (RC). Their results can be normalized, taking the ratio of the $\mathrm{RC}$ to the laser spot radius (SR); this shows that, for $2.4<\mathrm{RC} / \mathrm{SR}<5$, the increase of the maximum compressive stress compared to a flat surface is between $17 \%$ and $8 \%$. Assuming a linear variation between these two extremes, the value of $\mathrm{RC} / \mathrm{SR}=4$ used in the present work would result in an increase of about $14 \%$ compared to the flat case. A comparison with the results discussed above (i.e., an increment equal to $16 \%$ ) shows a good consistency for this estimate.

\section{Conclusions}

Laser peening without coating is a promising treatment for aluminum alloys. The outcomes of this work, focusing on $\mathrm{LPwC}$ applied at a notch, could be of interest for those applications in 
which the structural integrity is severely affected by the presence of holes and notches, such as aircraft components.

In summarizing, the following can be drawn from our observations:

- The fatigue life of the peened samples shows an improvement over that of the untreated ones, suggesting that laser peening without coating could enhance the fatigue behavior of notched components, similarly to conventional laser shock peening.

- The FEM results indicate that deep compressive residual stresses are induced in the treated area after $\mathrm{LPwC}$, which are known to obstruct fatigue crack growth, and are deemed to be the main reason for the improved fatigue life observed in the tests.

- The Brinell tests confirmed the ability of LPwC to increase surface hardness, possibly improving the wear performances of the peened specimens, which, together with the enhanced fatigue properties, could make this treatment appealing for applications such as lugs and bolted joints.

What has been presented here suggests that laser peening without coating has the potential to improve the fatigue behavior of aluminium components, even when it is applied directly at a notch. In this regard, the $\mathrm{LPwC}$ technology could emerge as an alternative to conventional LSP.

Author Contributions: Conceptualization, E.T. and N.Z.; data curation, E.T. and N.Z.; formal analysis, E.T. and N.Z.; investigation, E.T. and N.Z.; methodology, E.T. and N.Z.; software, N.Z.; supervision, E.T.; validation, N.Z.; writing (original draft), E.T.; writing (review and editing), E.T. and N.Z.

Funding: This research received no external funding.

Acknowledgments: The authors are thankful to Paolo Proli for technical support, Goran Ivetic and Ivan Meneghin for the help in the tests.

Conflicts of Interest: The authors declare no conflict of interest.

\section{References}

1. Fairand, B.P.; Clauer, A.H.; Jung, R.G.; Wilcox, B.A. Quantitative assessment of laser-induced stress waves generated at confined surfaces. Appl. Phys. Lett. 1974, 25, 431-433. [CrossRef]

2. Fabbro, R.; Fournier, J.; Ballard, P.; Devaux, D.; Virmont, J. Physical study of laser-produced plasma in confined geometry. J. Appl. Phys. 1990, 68, 775-784. [CrossRef]

3. Sano, Y.; Mukai, N.; Okazaki, K.; Obata, M. Residual stress improvement in metal surface by underwater laser irradiation. Nucl. Instrum. Methods Phys. Res. Sect. B Beam Interact. Mater. Atoms. 1997, 121, $432-436$. [CrossRef]

4. Montross, C.S.; Wei, T.; Ye, L.; Clark, G.; Mai, Y.-W. Laser shock processing and its effects on microstructure and properties of metal alloys: A review. Int. J. Fatigue 2002, 24, 1021-1036. [CrossRef]

5. Rubio-González, C.; Ocaña, J.L.; Gomez-Rosas, G.; Molpeceres, C.; Paredes, M.; Banderas, A.; Porro, J.; Morales, M. Effect of laser shock processing on fatigue crack growth and fracture toughness of 6061-T6 aluminium alloy. Mater. Sci. Eng. A 2004, 386, 291-295. [CrossRef]

6. Gao, Y.K. Improvement of fatigue property in 7050-T7451 aluminium alloy by laser peening and shot peening. Mater. Sci. Eng. A 2011, 528, 3823-3828. [CrossRef]

7. Sano, Y.; Masaki, K.; Ochi, Y.; Altenberger, I.; Scholtes, B. Laser Peening without Coating as a Surface Enhancement Technology. J. Laser Micro Nanoeng. 2006, 1, 161-166. [CrossRef]

8. Ivetic, G.; Meneghin, I.; Troiani, E.; Molinari, G.; Lanciotti, A.; Ristori, V.; Ocaña, J.L.; Morales, M.; Porro, J.A.; Polese, C.; et al. Characterisation of Fatigue and Crack Propagation in Laser Shock Peened Open Hole 7075-T73 Aluminium Specimens. In ICAF 2011 Structural Integrity: Influence of Efficiency and Green Imperatives, Proceedings of the 26th Symposium of the International Committee on Aeronautical Fatigue, Montreal, QC, Canada, 1-3 June 2011; Komorowski, J., Ed.; Springer: Dordrecht, The Netherlands, 2011; pp. 855-866.

9. Karthik, D.; Swaroop, S. Laser peening without coating-An advanced surface treatment: A review. Mater. Manuf. Process. 2017, 32, 1565-1572. [CrossRef]

10. Kashaev, N.; Ventzke, V.; Horstmann, M.; Chupakhin, S.; Riekehr, S.; Falck, R.; Maawad, E.; Staron, P.; Schell, N.; Huber, N. Effects of laser shock peening on the microstructure and fatigue crack propagation behaviour of thin AA2024 specimens. Int. J. Fatigue 2017, 98, 223-233. [CrossRef] 
11. Troiani, E.; Taddia, S.; Meneghin, I.; Molinari, G. Fatigue Crack Growth in Laser Shock Peened Thin Metallic Panels. Adv. Mater. Res. 2014, 996, 775-781. [CrossRef]

12. Yang, J.-M.; Her, Y.C.; Han, N.; Clauer, A. Laser shock peening on fatigue behaviour of 2024-T3 Al alloy with fastener holes and stopholes. Mater. Sci. Eng. A 2001, 298, 296-299. [CrossRef]

13. Ivetic, G.; Meneghin, I.; Troiani, E.; Molinari, G.; Ocaña, J.; Morales, M.; Porro, J.; Lanciotti, A.; Ristori, V.; Polese, C.; et al. Fatigue in laser shock peened open-hole thin aluminium specimens. Mater. Sci. Eng. A 2012, 534, 573-579. [CrossRef]

14. Dorman, M.; Toparli, M.B.; Smyth, N.; Cini, A.; Fitzpatrick, M.E.; Irving, P.E. Effect of laser shock peening on residual stress and fatigue life of clad 2024 aluminium sheet containing scribe defects. Mater. Sci. Eng. A 2012, 548, 142-151. [CrossRef]

15. Peyre, P.; Fabbro, R.; Merrien, P.; Lieurade, H.P. Laser shock processing of aluminium alloys. Application to high cycle fatigue behaviour. Mater. Sci. Eng. A 1996, 210, 102-113. [CrossRef]

16. Vasu, A.; Grandhi, R.V. Effects of curved geometry on residual stress in laser peening. Surf. Coat. Technol. 2013, 218, 71-79. [CrossRef]

17. ASTM International. ASTM E10-18 Standard Test Method for Brinell Hardness of Metallic Materials; ASTM International: West Conshohocken, PA, USA, 2018. [CrossRef]

18. Peyre, P.; Sollier, A.; Chaieb, I.; Berthe, L.; Bartnicki, E.; Braham, C.; Fabbro, R. FEM simulation of residual stresses induced by laser Peening. Eur. Phys. J. Appl. Phys. 2003, 23, 83-88. [CrossRef]

19. Angulo, I.; Cordovilla, F.; García-Beltrán, A.; Smyth, N.S.; Langer, K.; Fitzpatrick, M.E.; Ocaña, J.L. The effect of material cyclic deformation properties on residual stress generation by laser shock processing. Int. J. Mech. Sci. 2019, 156, 370-381. [CrossRef]

20. Chaboche, J.L. Time-independent constitutive theories for cyclic plasticity. Int. J. Plast. 1986, 2, 149-188. [CrossRef]

21. Chen, Y.; Clausen, A.H.; Hopperstad, O.S.; Langseth, M. Stress-strain behaviour of aluminium alloys at a wide range of strain rates. Int. J. Solids Struct. 2009, 46, 3825-3835. [CrossRef]

22. Chen, X.; Peng, Y.; Peng, S.; Yao, S.; Chen, C.; Xu, P. Flow and fracture behaviour of aluminium alloy 6082-T6 at different tensile strain rates and triaxialities. PLoS ONE 2017, 12, e0181983. [CrossRef]

23. Langer, K.; Olson, S.; Brockman, R.; Braisted, W.; Spradlin, T.; Fitzpatrick, M.E. High strain-rate material model validation for laser peening simulation. J. Eng. 2015, 13, 150-157. [CrossRef]

24. Trdan, U.; Porro, J.A.; Ocaña, J.L.; Grum, J. Laser shock peening without absorbent coating (LSPwC) effect on 3D surface topography and mechanical properties of 6082-T651 Al alloy. Surf. Coat. Technol. 2012, 208, 109-116. [CrossRef]

25. Berthe, L.; Fabbro, R.; Peyre, P.; Tollier, L.; Bartnicki, E. Shock waves from a water-confined laser-generated plasma. J. Appl. Phys. 1997, 82, 2826-2832. [CrossRef]

26. Benedetti, M.; Bortolamedi, T.; Fontanari, V.; Frendo, F. Bending fatigue behaviour of differently shot peened Al 6082 T5 alloy. Int. J. Fatigue 2004, 26, 889-897. [CrossRef]

27. Trdan, U.; Skarba, M.; Ocaña, J.L. Laser shock peening effect on the dislocation transitions and grain refinement of Al-Mg-Si alloy. Mater. Character. 2014, 97, 57-68. [CrossRef]

28. Hfaiedh, N.; Peyre, P.; Song, H.; Popa, I.; Ji, V.; Vignal, V. Finite element analysis of laser shock peening of 2050-T8 aluminium alloy. Int. J. Fatigue 2015, 70, 480-489. [CrossRef]

(C) 2019 by the authors. Licensee MDPI, Basel, Switzerland. This article is an open access article distributed under the terms and conditions of the Creative Commons Attribution (CC BY) license (http://creativecommons.org/licenses/by/4.0/). 